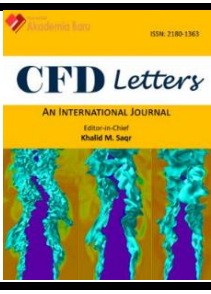

\title{
2D CFD Simulation Study on the Performance of Various NACA Airfoils
}

\author{
Mark Jason Thomas Loutun' ${ }^{1}$, Djamal Hissein Didane ${ }^{2,}{ }^{*}$, Mohd Faizal Mohideen Batcha², Kamil \\ Abdullah², Mas Fawzi Mohd Ali², Akmal Nizam Mohammed², Lukmon Owolabi Afolabi² \\ 1 Department of Mechanical Engineering, Faculty of Mechanical and Manufacturing Engineering, Universiti Tun Hussein Onn Malaysia, 86400 \\ Parit Raja, Batu Pahat, Johor, Malaysia \\ 2 Center for Energy and Industrial Environment Studies, Universiti Tun Hussein Onn Malaysia 86400 Parit Raja, Batu Pahat, Johor, Malaysia
}

ARTICLE INFO ABSTRACT

\section{Article history:}

Received 30 January 2021

Received in revised form 19 April 2021

Accepted 20 April 2021

Available online 26 April 2021

\section{Keywords:}

CFD simulations; NACA airfoils; wind turbine; torque coefficient; power coefficient

\begin{abstract}
The wind is an energy source that has the properties of a clean, free, and readily available energy source. However, the efficiency of the existing rotors used to harness wind power is still not satisfactory. Thus, in this current study, the development and aerodynamic performance investigation of ten NACA airfoils comprising of five symmetrical and five non-symmetrical airfoils have been analyzed through the computational fluids dynamic (CFD) simulation approach. The main motive of this study was to investigate the aerodynamic performance of NACA airfoils to be used on a vertical axis wind turbine (VAWT), which will assist in further understanding the physics of the interaction between airflow and the wind turbine blades. The simulation was performed using two-dimensional computational models based on an unsteady state K-omega Shear Stress Transport (SST) turbulence model. This study covers a parametric study based on the variations of tip-speed ratios and constant wind velocity. The aerodynamic performances are evaluated in terms of torque, torque coefficient, and also power coefficient. The performance of NACA0018 was found to be the best among the other airfoils with a power coefficient of 0.3. NACA0010 displayed the lowest power coefficient among the other airfoils but had a more extensive operating range compared to the other airfoils. However, for nonsymmetrical NACA airfoils, NACA2421 scored the highest power coefficient, followed by NACA4412. It was also found that most of the non-symmetrical NACA airfoils can operate at a higher range of tip-speed ratios compared to the symmetrical NACA airfoils.
\end{abstract}

\section{Introduction}

Over the past decades, large companies involving in energy production have been exploring and venturing into renewable energy systems to replace the current use of non-renewable conventional energies. Despite their effort to reduce the usage of fossil fuels such as coals and nuclear which is the main contributor to climate change due to excessive emission of carbon dioxide, the world is still not on track in meeting the international climate goals which were established under the Paris Agreement (IPCC) or international goals for sustainable development. According to IPCC 2018 Special

\footnotetext{
* Corresponding author.

E-mail address: djamal@uthm.edu.my (Djamal Hissein Didane)
}

https://doi.org/10.37934/cfdl.13.4.3850 
Report on $1.5^{\circ} \mathrm{C}$, it was reported that there would be approximately a decade left to maintain global warming below this level and avoid the worst effects of climate change. It is undeniable that our world inevitably requires electricity to power most of our technologies and devices, and it has become a necessity to have electricity in our daily life and activity. Unfortunately, the process of producing electricity is the primary cause of industrial air pollution in the United States, and a significant part of the world as most of our electricity comes from the use of coal, nuclear and other non-renewable power plants [1].

To heed the calls for a better chance to battle climate change and global warming, the world needs to reduce if not stop the use of fossil fuels, nuclear and coal which is currently used as the primary fuel to power the majority of heavy industrial machines such as gas turbine, diesel generator, and vehicles. For that reason, the world needs to further research and explore renewable energy technologies, which can substitute the use of fossil fuels in generating electricity [2,3]. Wind energy conversion has undergone significant growth worldwide, and this achievement can be proven with the development of horizontal axis wind turbine (HAWT) technologies, which is undeniably at the top of the market now [4,5]. Nevertheless, researchers have shown interest in wind energy that new alternative turbine technologies are being researched especially vertical axis wind turbines (VAWT) for building augmented (roof installation) for the urban environment. Vertical-axis wind turbines are known for their insensitivity to yaw angle, very low noise due to low tip speed ratios, and their mechanical and electrical heavy parts are ground positioned [6-8].

Moreover, the vertical axis wind turbines (VAWTs) are known for their vertical axis of rotation from the ground and perpendicular to the direction of the wind. Thanks to this design, the VAWT can rotate from any wind direction without the need to install a yaw mechanism that was generally used in large horizontal axis wind turbine (HAWT) $[9,10]$. One of the significant advantages of VAWT that pushes this type of turbine above others (HAWT) is the positioning of the VAWT main component where the generator and gearbox can be positioned at ground level. This type of setup offers a much simple tower design and certainly economical. Since most of the main components of the VAWT are ground level, it is relatively easier for maintenance to be conducted. However, there are major disadvantages of using this type of wind turbine (VAWT) as it usually will not self-start and requires external forces or mechanisms to force the rotor to rotate $[11,12]$.

Throughout the years, researchers and scholars had taken interest in investigating suitable airfoil for applications in wind turbines. In a numerical and experimental investigation of NACA 0015 airfoil done by Izzet et al., [13], they concluded that the drag and lift coefficient on NACA 0015 airfoil increases as the angle of attack increases. It was also observed that stalls will start to build up at a 16-degree angle of attack where the drag coefficient increased whereas the lift coefficient decreased. They also recorded an optimum lift coefficient at the same angle of attack of $16^{\circ}$. Overall, the optimum airfoil performance was measured at an $8^{\circ}$ angle of attack. However, a study conducted by Miller [14] found that the NACA 0015 airfoil experienced a critical loss of lift somewhere between 10 and 15 degrees of angle of attack. The experiment conducted was based on a wind tunnel being operated at a nominal speed of $17 \mathrm{~m} / \mathrm{s}$. It was also recorded that the theoretical values for lift coefficient matched closely to those measured but unfortunately begin to decrease after the 10 degrees point. Nonetheless, the drag coefficient values are found to be consistent. As for investigation on NACA 0018 airfoil, it was further proven that the lift coefficient is dependent on the angle of attack for the NACA 0018 airfoil at three different trailing radius ratios [15]. It was found through this investigation that at a high angle of attack between 12 and 15 degrees with a trailing edge radius of 0.04 , this setup is beneficial when considering the lift.

Another recent study on the variation of six NACA 4-digit airfoils consisting of NACA 0018, 0015, 0022, 2418 and NACA 4418 was used to investigate their start-up characteristics for H-Darrieus 
vertical axis wind turbine under free stream condition [16]. The results obtained favored the combination of NACA 2418 with an outward pitch angle of $1.5^{\circ}$ that recorded a $27 \%$ reduction in start-up time and therefore eliminate the plateau entirely in the operating time series. It was also concluded that the starting torque can also be greatly increased by using thicker aerofoil sections for the rotor [17]. A similar study was conducted in the hope to increase the performance of the H-rotor Darrieus turbine with new airfoils by testing twenty different symmetrical and non-symmetrical airfoils [18]. The airfoils comprised of NACA series, S-series, A-series and FX-series were tested at a speed ratio between 2 and 10 to obtain the characteristic performance of the rotor, torque and power coefficients. The study concluded that there is an increase in power output coefficient by $26.83 \%$ for the S-series specifically the S-1046 when compared to the other common symmetric NACA airfoils. This consequently increases the overall efficiency of this new design by $10.87 \%$ compared to the conventional design.

A comparison was done to compare the performance of NACA 6-series and NACA 4-digit airfoils for Darrieus wind turbines using a blade element/momentum theory and the study indicated that the power coefficient produced by the NACA 6-series is as great as the NACA 4-digit airfoils while also having a power coefficient-tip speed ratio that is broader and flatter [19]. By using the same approach of blade element momentum theory, two NACA airfoils were compared to predict the performance of wind turbine blades [20]. It was concluded in this study that the power coefficient depends on the tip speed ratio and will only reach maximum in a specific tip speed ratio and while in the presence of drag, the maximum power coefficient that can be produced is significantly less than the Betz limit at all tip speed ratios.

Nowadays, the aerodynamic characteristics of a wind turbine of airfoils can easily be predicted through a 2-D or 3-D simulation using computational fluids dynamics (CFD) software [21-23]. Wolfe and Ochs [24] had compared the calculated and experimental (CFD) aerodynamics coefficient of NACA 0021. It was reaffirmed in their conclusion that in order to attain accurate numerical simulations of flow in current generation wind turbine airfoils, two areas in CFD simulations need further investigation and development, which are transition prediction and turbulence modeling. This method was further validated by Langtry et al., [25] in their study of predicting 2D airfoil and 3D wind turbine performance using a transition model for general CFD codes. It was concluded that the transitional results matched the result of that experimental data, and this model would be well suited for the prediction of wind turbine aerodynamics.

In this study, additional research is conducted, which focused on using wind energy as a renewable energy source to replace the current use of fossil fuels in power generation and to further understand the physics of the interaction between airflow and the wind turbine blades. As the efficiency of the existing rotors used to harness wind power is still not satisfactory and requires further investigations, this study is set out to investigate the performance of ten variations symmetrical and non-symmetrical NACA 4-digit airfoils series while employing the 2D CFD simulations approach.

\section{Methodology}

\subsection{Governing Equations and Turbulence Model}

The governing equations in Computational Fluid Dynamics (CFD) software are the Navier-Stokes equations. It is based on the conservation law of fluid's physical properties. The general theory of conservation law is the change of properties, such as mass, momentum and energy which is decided by the input and output of an object. While ANSYS Fluent is a platform that solves mass and momentum conservation equations for all flows. As for this study, the conditions of flow applied are 
transient, two-dimensional, incompressible and viscous flow. Furthermore, the density of air can be assumed as constant due to the low wind speed applied in this simulation. The continuity equation, momentum equation and energy equation are shown in Eq. (1), Eq. (2) and Eq. (3), respectively.

The two-equation, $k$ - $\omega$ shear stress transport (SST) turbulence model was used as the turbulence model in the current simulation which consists of specific turbulent kinetic energy, $k$ and the turbulent dissipation rate, $\omega$, as in Eq. (3) and Eq. (4), respectively.

$\frac{D \rho}{D t}+\rho \frac{\partial U_{i}}{\partial x_{i}}=0$

$\underbrace{\rho \frac{\partial U_{j}}{\partial t}}+\underbrace{\rho U_{i} \frac{\partial U_{j}}{\partial x_{i}}}=-\underbrace{\frac{\partial P}{\partial x_{j}}}-\underbrace{\frac{\partial \tau_{i j}}{\partial x_{i}}}+\underbrace{\rho g_{j}}$

I II III IV V

where

I. Local change with time

II. Momentum convection

III. Surface force

IV. Molecular-dependent Momentum exchange (diffusion)

V. Mass force

$\frac{\partial(\rho k)}{\partial t}+\frac{\partial\left(\rho U_{i} k\right)}{\partial x_{i}}=\tilde{P}_{k}-\beta^{*} \rho k \omega+\frac{\partial}{\partial_{x_{i}}}\left[\left(\mu+\sigma_{k} \mu_{t}\right) \frac{\partial k}{\partial_{x_{i}}}\right]$

$\frac{\partial(\rho \omega)}{\partial t}+\frac{\partial\left(\rho U_{i} \omega\right)}{\partial x_{i}}=\alpha \rho S^{2}-\beta \rho k \omega^{2}+\frac{\partial}{\partial x_{i}}\left[\left(\mu+\sigma_{\omega} \mu_{t}\right) \frac{\partial \omega}{\partial x_{i}}\right]+2\left(1-F_{1}\right) \rho \sigma_{\omega, 2} \frac{1}{\omega} \frac{\partial k}{\partial x_{i}} \frac{\partial \omega}{\partial x_{i}}$

where $\tilde{P}_{k}$ is the rate of production of turbulent kinetic energy and $F_{1}$ is the blending function.

\subsection{Selection and Modelling of Airfoils}

Currently, many airfoil designs can be found on the airfoil database, but for this study, only ten relevant variations of the NACA series comprised of symmetrical and non-symmetrical airfoils are selected from the airfoil database available online. For this study, five airfoils are selected, each from symmetrical and non-symmetrical, respectively, that ranged from thin to thick airfoils so that the performance can be differentiated. Thus, the models investigated in this study are five symmetrical and five non-symmetrical NACA airfoils with a chord length of $0.08 \mathrm{~m}$ and an area of $1.2 \mathrm{~m}^{2}$.

After selecting the appropriate airfoils, the airfoils need to be modelled using computer-aided design (CAD) software. For this study, SolidWorks 2017 is used to model the airfoils and convert them into entities that are compatible to run simulations on a computational fluid dynamic (CFD) solver. To create an airfoil model in SolidWorks, we need the calculated coordinates of the airfoil, which is readily available in the airfoil database. Then, the coordinates are rearranged and reformatted using Microsoft Excel before transferring the data into SolidWorks, where the coordinates can be used to automatically produced the airfoil model, as shown in Figure 1. 


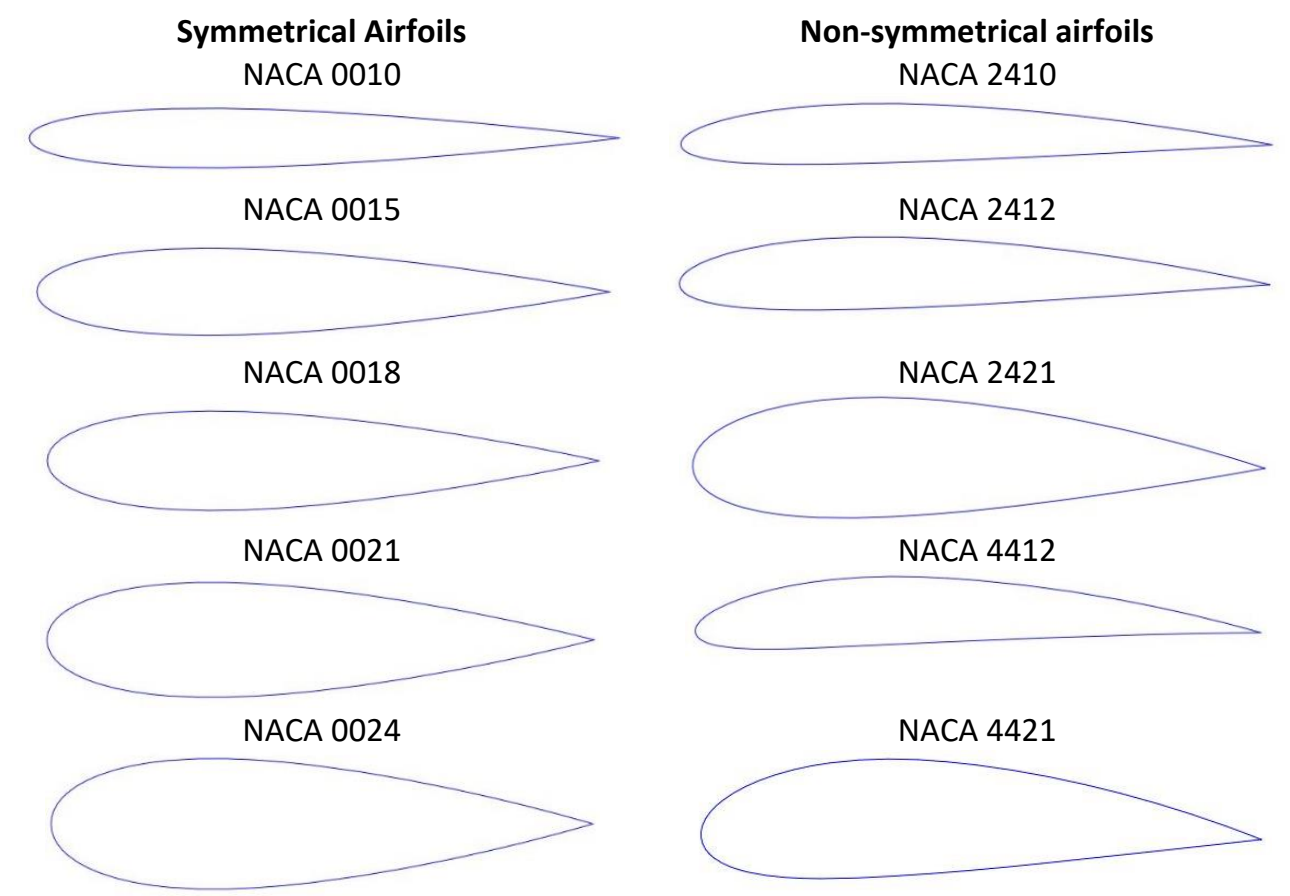

Fig. 1. Selected symmetrical and non-symmetrical airfoils

\subsection{CFD Domain Discretization and Model Set Up}

After importing the model into ANSYS, the square type domain with a ratio of 20 between the square domain length and the rotor radius, as suggested from the previous study by Mohammed [18] was sketched using Design Modeler. The process of discretizing the computational domain to multiple numbers of cells or elements is called meshing. The number of cells for the mesh can be adjusted from the size of elements through the sizing option while implementing the all-triangles method for this study. The concentration of the mesh cells is focused around the airfoil body. In order to achieve a better mesh quality and an accurate solution during the simulation, inflation is applied around the airfoil edge, where the first layer thickness is set to maximum layers of 20 and a growth rate of 1 . Next, the adaptive sizing from the mesh sizing option is applied to get a more uniform mesh cell around the domain, while inflation is added for more uniform mesh cells around the airfoil edges, as shown in Figure 2 and Figure 3, respectively.

The boundary conditions are a crucial component in the simulation process as they can be used as flow variables of the intended physical model to specify the boundaries. This will also provide a specific solution by directing the flow of the motion. Therefore, it is essential to specify the boundary conditions of every one of the geometries of the component precisely during the pre-processing stage as the solution of flow problems depended on it. Any unassigned boundary conditions could cause errors to occur during the simulations or leads to inaccurate results. This study consists of several boundary conditions, namely, inlet, outlet, wall, and interface.

The velocity inlet with steady distribution is applied at the inlet at the direction of the $x$-axis, and pressure outlet boundary conditions are assigned along the $\mathrm{x}$-axis directly opposite to the velocity inlet boundary conditions. The wall boundary condition with a no-slip condition is applied to the airfoil, and also the symmetrical wall boundary condition is assigned the sidewalls. For this study, there are two interfaces, which are interface-in and interface-out created around the airfoil separated by a certain distance. There is also a rotating and non-rotating interface where the magnitude and direction of the velocity can be applied to the rotating interface. For the solution method, the coupled algorithm was used for the pressure-velocity coupling scheme. 


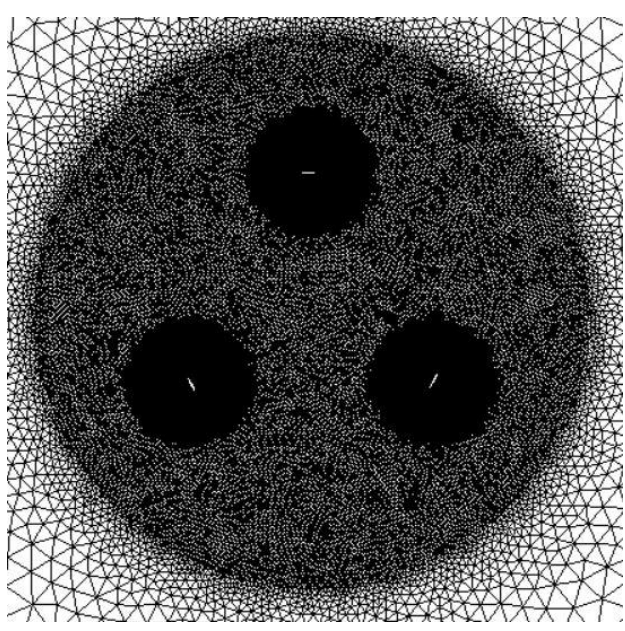

Fig. 2. Full meshing on the rotating domain and flapping domain

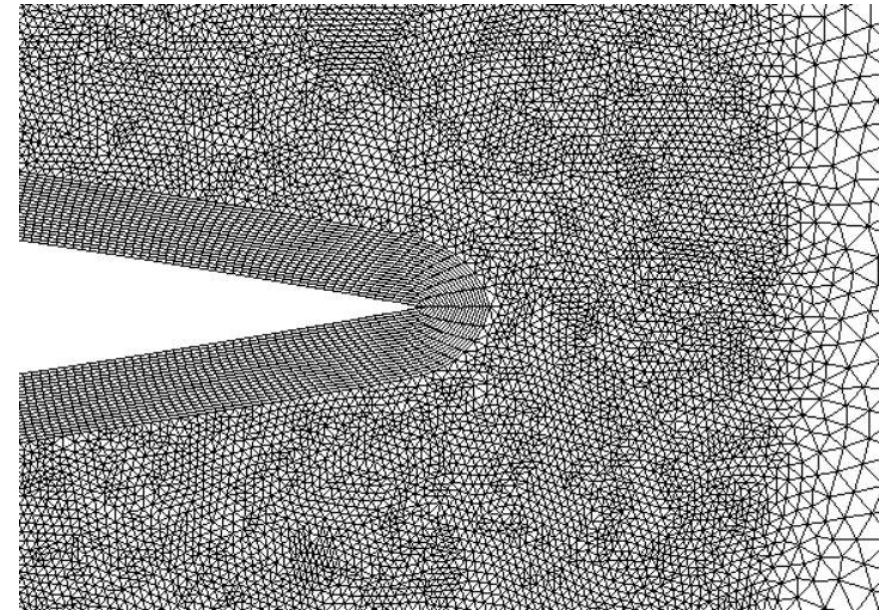

Fig. 3. Close up of mesh generated around the airfoil edges

\section{Results}

This subtopic discussed the aerodynamic performance of symmetrical and non-symmetrical NACA airfoils, which were computed by using the CFD simulation technique. After the validation of the results was accepted, the simulation is proceeded by adopting its parameters to be studied, such as the tip-speed ratio. The performance investigations are presented in terms of torque coefficient and power coefficient, pressure contours, velocity contours, and streamlines, along with the design model.

\subsection{Grid Independence and Model Validation}

The grid-independent study is a critical process in which a mesh study must be done before adopting the suitable mesh settings to the rest of the simulations. In this study, adaptive re-meshing was performed to the airfoil with six different sizes of elements. It was observed that the numerical torque value becomes stable as the number of elements increases and reached one million elements. Thus, for this study, the element size of 0.00025 has been selected for the rest of the mesh as it has a moderate number of elements and a relative error of $3 \%$, which is suitable and consumes less time to solve, as shown in Table 1.

The present simulation results were validated against the previous study performed by Mohammed [18]. As shown in Figure 4, the validation process was in terms of the power coefficient with respect to the corresponding tip speed ratio (TSR) between the current results and previous results using the same NACA0021 airfoil. From the graph, it can be observed that the trend between current and previous study results shows a similar trend from beginning to the end, which is promising and acceptable. The relative error was calculated to be around $11.97 \%$ on average.

Table 1

Grid-independence test

\begin{tabular}{llllll}
\hline No & Size of Elements & No of Elements & Skewness & Torque Output (Nm) & Relative error (\%) \\
\hline 1 & 0.004 & 230125 & 0.8868 & 5.7089321 & 19.865 \\
2 & 0.002 & 242213 & 0.86386 & 4.6450518 & 2.472 \\
3 & 0.001 & 283285 & 0.84878 & 4.0318518 & 15.347 \\
4 & 0.0005 & 429737 & 0.84977 & 5.1812354 & 8.785 \\
5 & 0.00025 & 968060 & 0.8714 & 4.6163855 & 3.0741 \\
6 & 0.000125 & 3041530 & 0.84231 & 4.6498342 & 2.372 \\
\hline
\end{tabular}




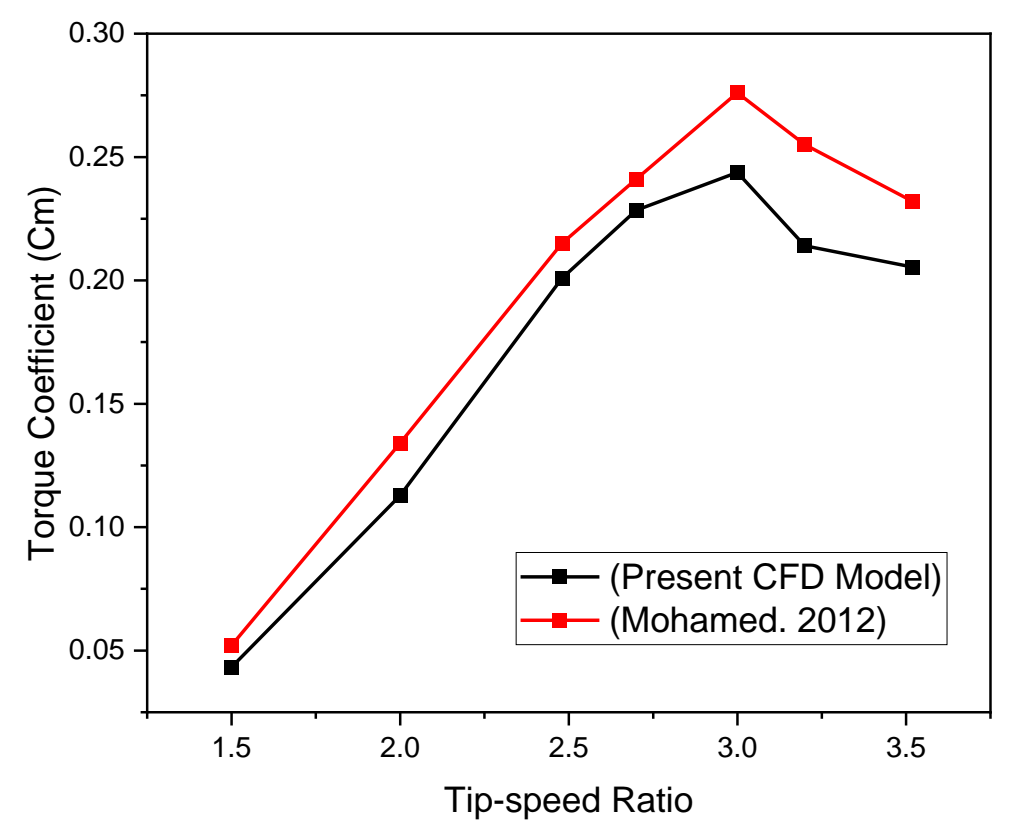

Fig. 4. Validation of the present results with previous study results

\subsection{Torque Coefficient}

Primarily in a wind turbine, the performance of the wind turbine is usually determined by its aerodynamic characteristics such as the torque and also power coefficient. Thus, the numerical torque coefficients exerted by both symmetrical and non-symmetrical airfoil through CFD simulations are plotted in a graph, as shown in Figure 5. The tip-speed ratio is tested in the range between 2.2 and 2.8 at a constant wind velocity of $9 \mathrm{~m} / \mathrm{s}$.

From the graph in Figure 5, it can be observed that the trend line of torque coefficient for all the NACA airfoils are quite similar where the coefficient values increase to a certain point, which is known as the optimum operating point of tip-speed ratio and then start to decline. However, such an operating point is slightly different from one airfoil to another. Moreover, both symmetrical and nonsymmetrical airfoils exhibit a similar low torque coefficient at the lowest tip-speed ratio for the study, which is at TSR=2.2 in which NACA2410 and NACA0010 had generated negative torque coefficient with the latter being the lowest among the ten airfoils at $-0.02925091 \mathrm{Nm}$.

Usually, these negative values of torque can be caused by flow separations that occur when the wind is passing through increasing pressure on the blade, which causes static stall as well. The negative torque indicated that the turbine would be unable to start except by installing a drag device to assist it [26]. For that, further research needs to be done to study the tangential force and static torque on the blade, which could affect the starting capability of the wind turbine, which is not covered in the current study.

On the contrary, NACA0021 had showcased the highest torque value at TSR $=3.15$ with a torque coefficient of $0.061477079 \mathrm{Nm}$ while the second highest is NACA0018 at the same TSR with a torque coefficient of $0.057949587 \mathrm{Nm}$. As such, the torque coefficient for all the airfoils showed increment as the tip speed ratio increases with peak TSR of 3.15 for NACA0021, NACA0018, NACA4412, and NACA4421 before they start declining again at a higher tip speed ratio while the other airfoils only start declining at (TSRs $=5.25,6.2$, and 7.2 ) with the lowest torque generated by all airfoils at highest TSR of 8.2. This indicates that thicker airfoil can only generate high torque coefficients at a certain tip speed ratio while thinner airfoil can still generate a high torque coefficient at a higher tip speed ratio. 


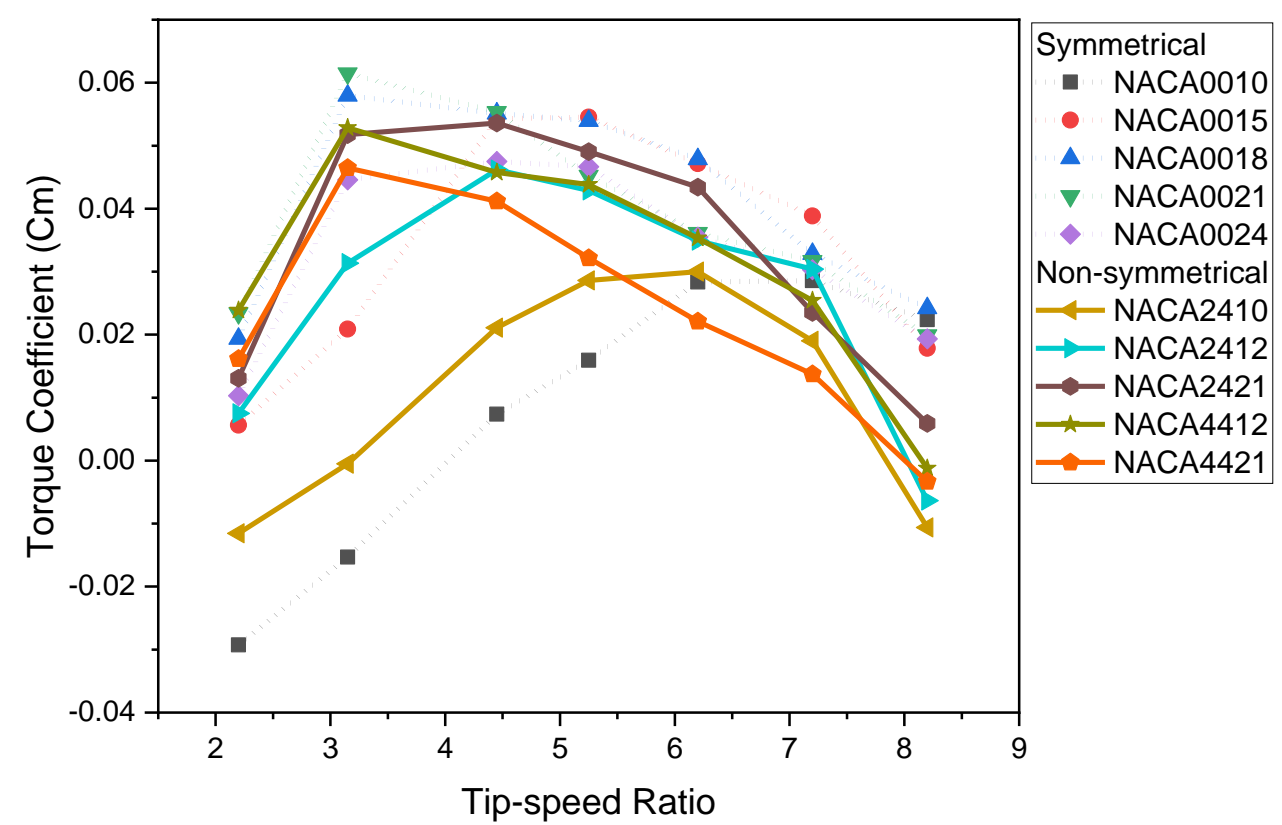

Fig. 5. Torque coefficients against the tip-speed ratio for symmetrical and nonsymmetrical airfoils

\subsection{Comparison of Power Coefficient}

The power coefficient can be defined as the ratio of the power extracted by the wind turbine relative to the energy available in the wind stream [27]. Thus, by referring to the aerodynamic analysis theory and also the numerical value of the torque coefficients of the NACA airfoils obtained through 2D simulations in CFD, the power coefficients (Cp) are obtained and plotted in a graph as shown in Figure 6.

Figure 6 shows the numerical value of the power coefficients $(C p)$ as a function of the tip-speed ratio, where the power coefficient values of all the NACA airfoils are analyzed and plotted. From the graph, it can be observed that both symmetrical and non-symmetrical airfoil share the same trend line as in the torque coefficient, where the numerical power coefficient increases as the speed ratio increased to an absolute peak of tip-speed ratio. The only apparent difference is that for symmetrical NACA airfoil, the power coefficient value declined gradually after the speed ratio reached the peak value, which is around (TSR $=6.2-8.2$ ).

In contrast, the power coefficient for the non-symmetrical NACA airfoil will decline rapidly around the same speed ratio. For the symmetrical airfoil, it is noticeable that NACA0018 exhibits the highest power coefficient (Cp) at TSR 6.2 with a value of 0.2968795 followed closely by NACA0015 with a slightly lower power coefficient of 0.292263 at the same tip speed ratio with a percentage difference of $1.57 \%$ between the two values. On the other hand, the lowest power coefficient can be observed coming from NACA0010, which is the thinnest airfoil among the symmetrical with a peak power coefficient value of 0.205698 at TSR $=7.2$. However, it is notable that NACA0010 alongside NACA0021 has a more extensive operating range of TSR peaking at TSR $=7.2$ before declining at TSR $=8.2$.

As for the performance of non-symmetrical NACA airfoil, it can be seen that NACA2421 generated the highest power coefficient at peak TSR of 6.2 with a recorded value of 0.2691065 before starting to decline at a higher speed ratio. NACA4412 followed this trend with a power coefficient of 0.2300215 at TSR $=5.25$. It is to be noted that most of the non-symmetrical airfoil can still generate higher power coefficient peaking at (TSR $=6.2$ and 7.2 ) before declining rapidly at TSR $=8.2$, which indicates that the non-symmetrical airfoil is less efficient in higher speed ratio. 
Comparing both the performance of symmetrical and non-symmetrical NACA airfoils side by side, it is apparent that NACA0018 proved to have the highest power coefficient among all the NACA airfoils followed by NACA2421 from non-symmetrical airfoil with a percentage difference of $9.814 \%$ between the two NACA airfoils with both functioning at the same TSR of 6.2. However, the performance of all the non-symmetrical airfoils tends to drop drastically at TSR $=8.2$ with NACA2410, NACA2412, NACA4412, and NACA4421 reaching a negative power coefficient. Nonetheless, it is worth mentioning that the Betz limit of power coefficient is only 0.593 and determined when the air velocity leaving the turbine is $1 / 3$ of the incoming air, which is the wind velocity [26].

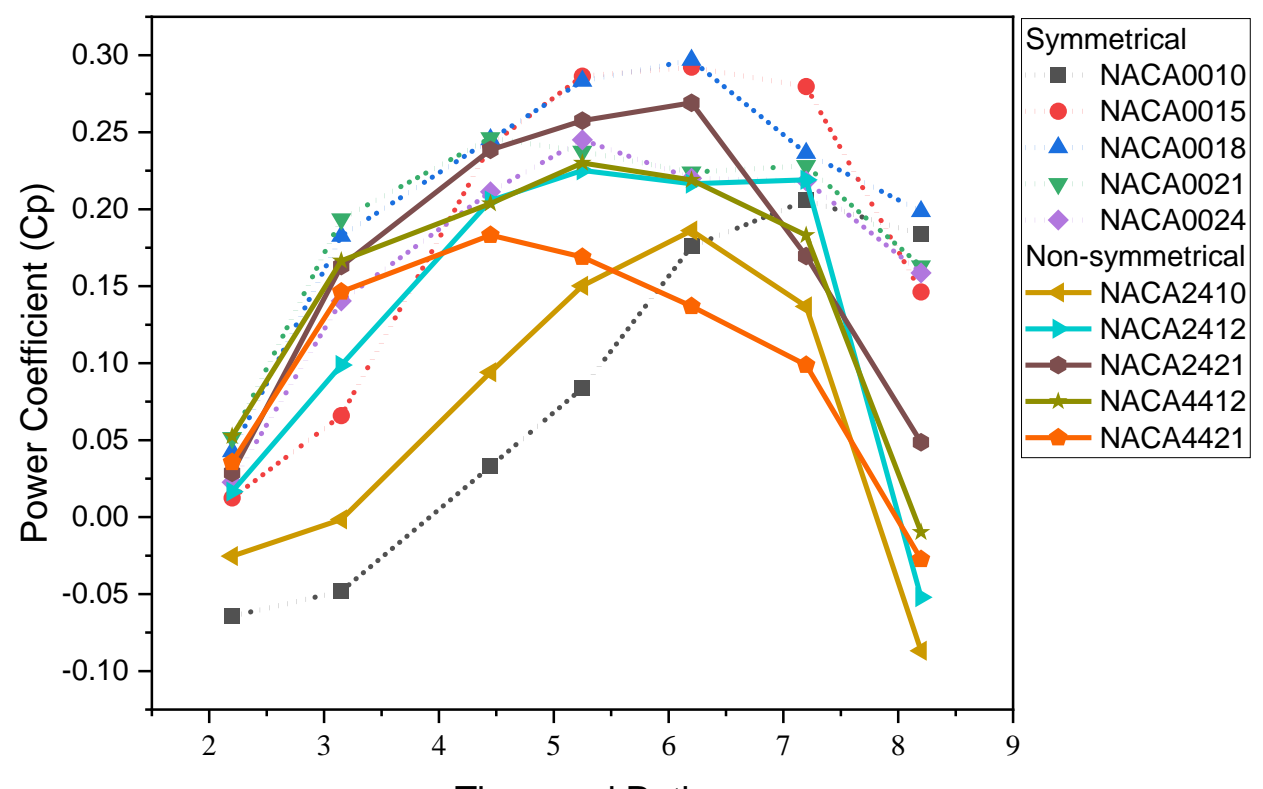

Tip-speed Ratio

Fig. 6. Power coefficients against tip-speed ratio for symmetrical and nonsymmetrical airfoils

Furthermore, the pressure contours are illustrated in Figure 7 and Figure 8, where it is evident that higher pressure contours occur at the leading edge of all the blades. This showed that stagnation occurred at all the leading edges of the blades as the velocity is significantly lower at that point before flowing into the upper and lower body of the blades. The pressure distribution on the lower body of the blade is still present, although the blades are rotating at high RPM, which explains the slightly lower torque coefficient obtained by NACA0018 at TSR $=6.2$. On the other hand, it can be observed that the pressure gradient visible on the leading edge of the blade of NACA4421 is slightly higher than that of the NACA0018. Moreover, the pressure distribution on the upper and lower body of all the blades of NACA4421 is noticeable, which means that there might be a flow separation occurred along with the blades and consequently trigger a backflow caused by the vortex at the trailing edge. This is explained by the intense negative pressure on that region filled with backflow. Unfortunately, such an occurrence greatly affected the performance of the NACA4421, which has the lowest power coefficient among the other airfoils. Nonetheless, it is noteworthy to mention that pressure difference acting on the model had a more significant impact on the output results, while the difference in viscosity does not affect as much. 


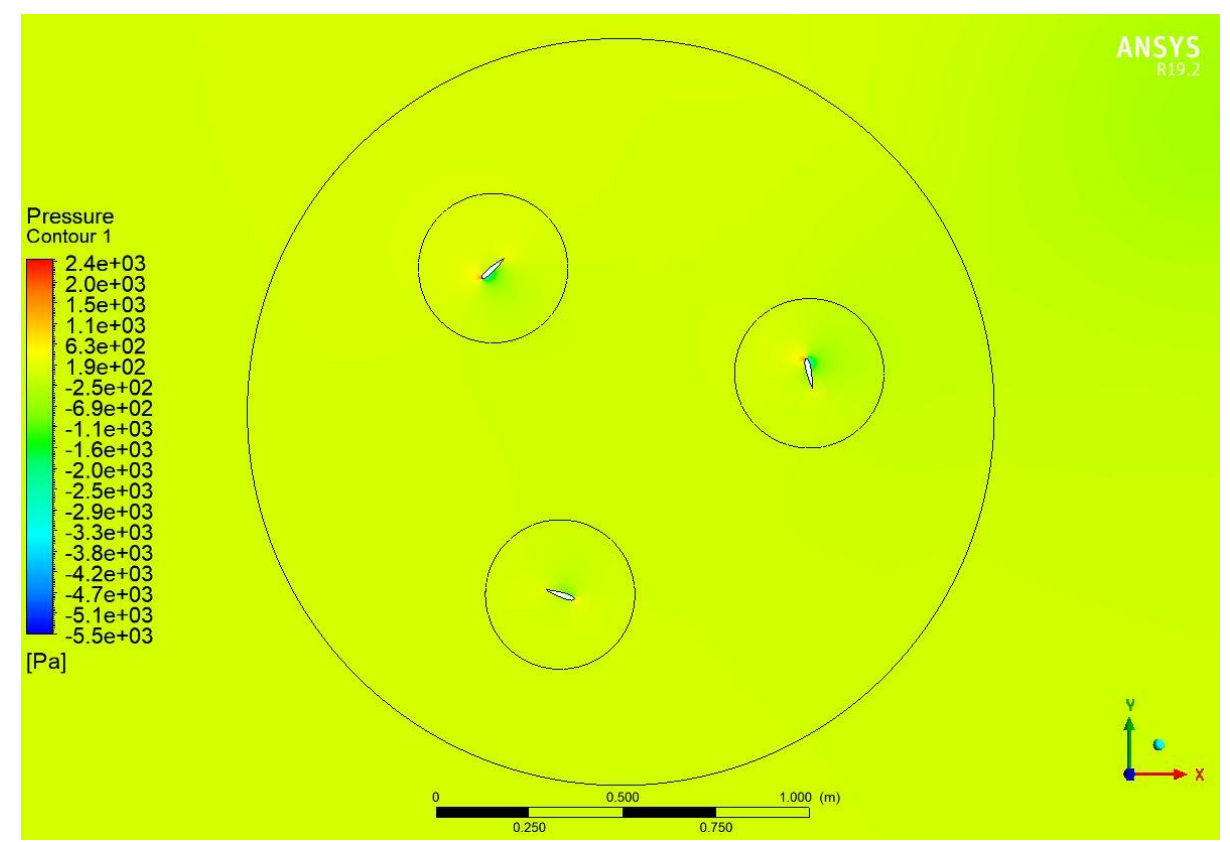

Fig. 7. Pressure contour of NACA0018 at TSR 6.2

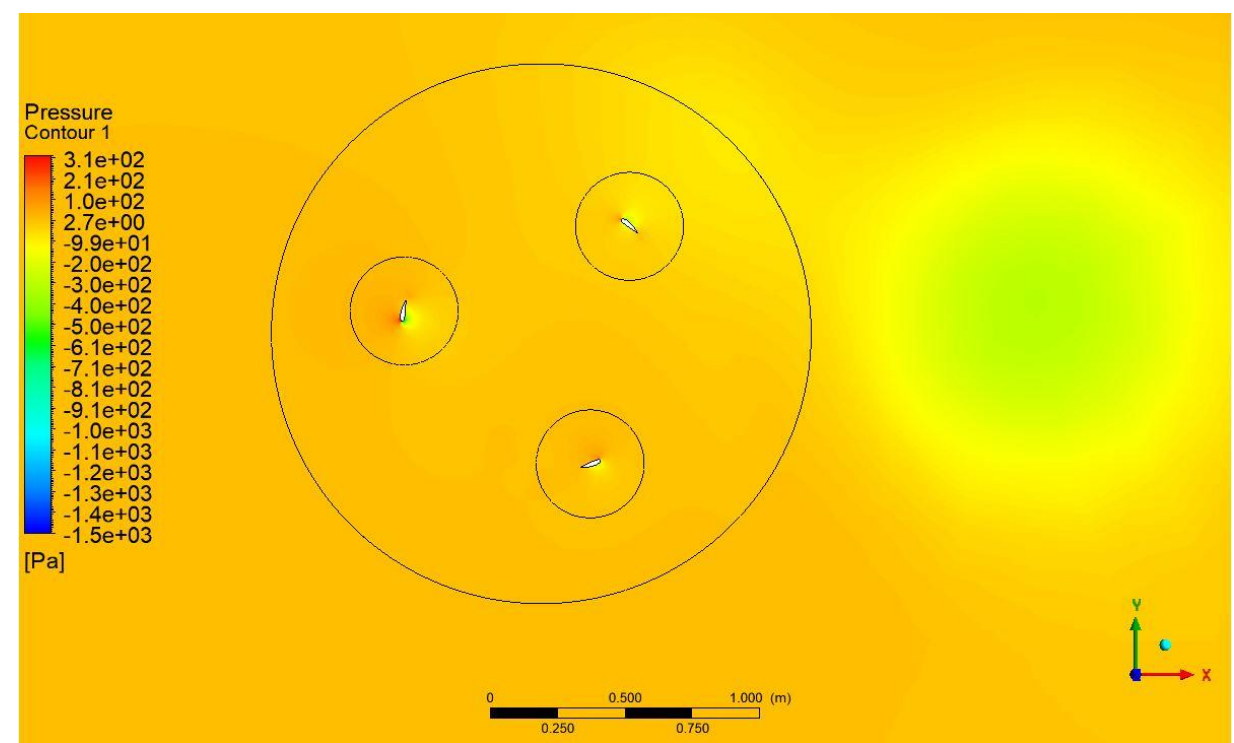

Fig. 8. Pressure contour of NACA4421 at TSR 4.45

Figure 9 and Figure 10 illustrate the velocity contours of NACA0018 and NACA4421 with TSR= 6.2 and 4.45, respectively. Logically, when the incoming air comes in contact with the blades, the rotor will start to spin and consequently force the wind around the rotor to move in a circular pattern as well. This circular movement of the wind around the rotor will somehow affect the performance of the rotor due to the velocity of the incoming wind on returning blades being reduced and consequently generating resistance between the blade surface and the incoming air.

By analyzing the velocity contour in Figure 9 and Figure 10, it can be seen that the velocity at the leading edge of all the blades is lower, which supported the occurrence of stagnation that was mentioned previously. It is also notable that a small wind vortex had built up inside the rotor, given that relatively low velocity can be observed inside the rotor. On the other hand, the velocity contour in Figure 9 also supported that flow separation had occurred along the blade as it can be seen that there are irregular wind velocities along the blade. This phenomenon had caused a significant rise in velocity in the wake region, which can be observed on the enormous green spot in Figure 9. 


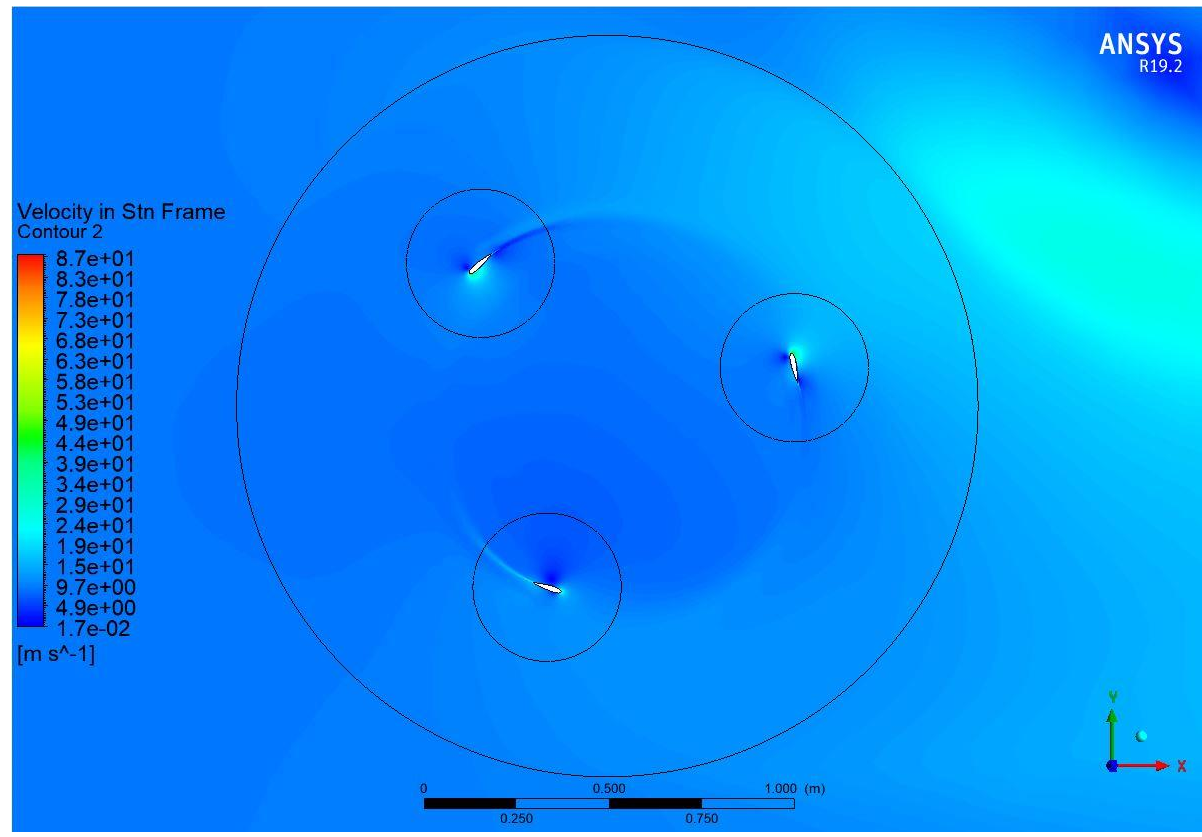

Fig. 9. Velocity contour of NACA0018 at TSR 6.2

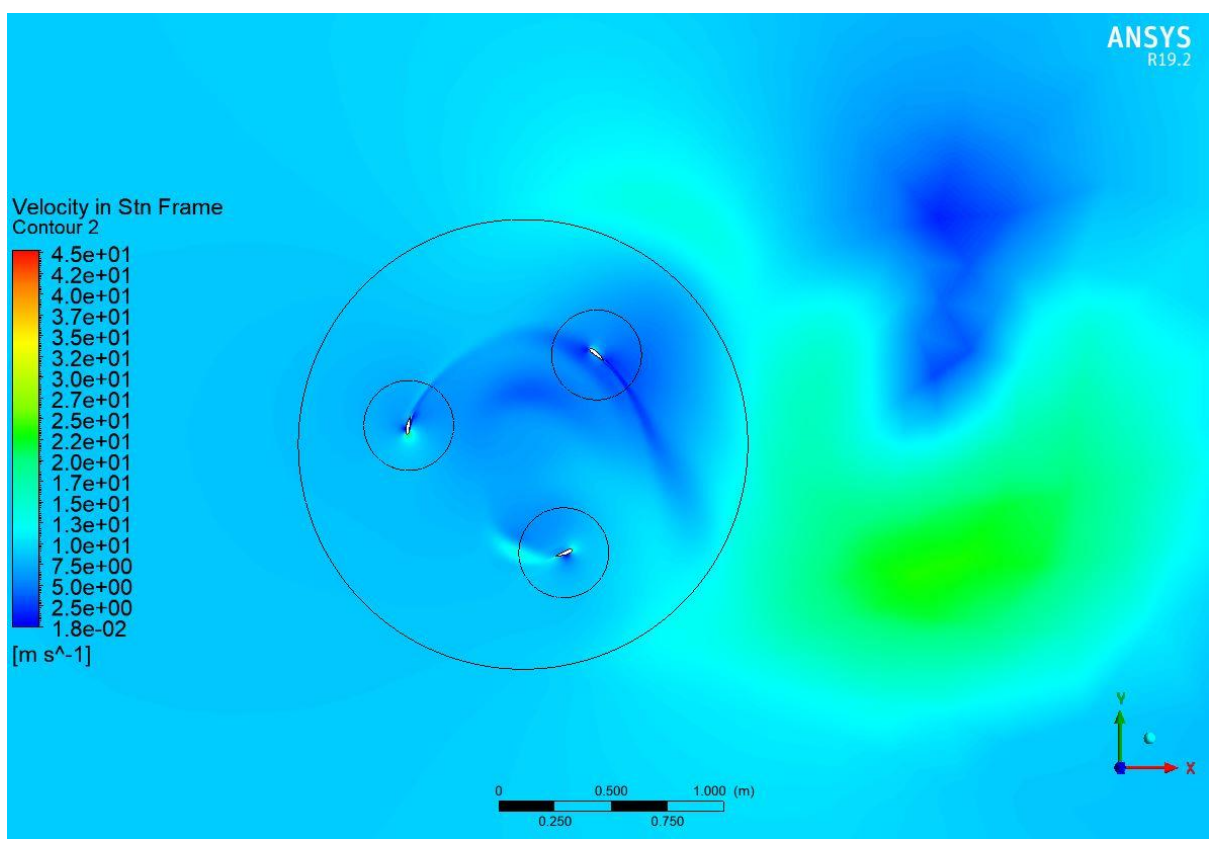

Fig. 10. Velocity contour of NACA4421 at TSR 4.45

\section{Conclusions}

In this study, the performance analysis of 10 symmetrical and non-symmetrical NACA airfoils has been performed through 2-Dimensional computational fluid dynamics (CFD) simulations. The models investigated in the study consist of five symmetrical and five non-symmetrical NACA airfoils at various tip-speed ratios ranging from 2.2 up to 8.2 at a constant incoming wind velocity of $9 \mathrm{~m} / \mathrm{s}$. The simulation was performed based on the unsteady state K-omega Shear Stress Transport (SST) turbulence model.

From the results obtained, it can be concluded that the main objective which is to evaluate and compare the aerodynamic performance of symmetrical and non-symmetrical NACA airfoils has been achieved successfully. The results show that NACA0018 exhibits the highest power coefficient among 
the other NACA airfoils operating at TSR $=6.2$ with a power coefficient of 0.2968795 followed closely by NACA0015 with a difference of $1.57 \%$ lower than NACA0018 at the same speed ratio. In contrast, NACA0010 displayed the lowest power coefficient among the other airfoils but had a more extensive operating range compared to the other airfoils. As for non-symmetrical NACA airfoils, NACA2421 scored the highest power coefficient of 0.2691065 at TSR $=6.2$, followed by NACA4412 with the power coefficient of 0.2300215 at TSR $=5.25$. The only apparent difference between symmetrical and non-symmetrical NACA airfoils in terms of performance is that most of the non-symmetrical NACA airfoils can still operate at a higher range of tip-speed ratio. However, they decline shortly after reaching the optimum tip-speed ratio. While symmetrical NACA airfoils, on the other hand, had a lower optimum speed ratio, but they decline gradually when operated over their optimum tip-speed ratio.

\section{Acknowledgement}

The authors would like to acknowledge the Publisher's Office, Universiti Tun Hussein Onn Malaysia for the financial support under Publishing Fund (E15216).

\section{References}

[1] Ren 21, "Why is renewable energy important?," REN21 Network WorldWatch Institute, 2019.

[2] Didane, Djamal Hissein. "Wind and Solar Assessment in the Sahelian Zone of Chad." International Journal of Integrated Engineering 10, no. 8 (2018). https://doi.org/10.30880/ijie.2018.10.08.026

[3] Didane, Djamal Hissein, Abas Ab Wahab, Syariful Syafiq Shamsudin, Nurhayati Rosly, Mohd Fadhli Zulkafli, and Sofian Mohd. "Assessment of wind energy potential in the capital city of Chad, N'Djamena." In AIP Conference Proceedings, vol. 1831, no. 1, p. 020049. AIP Publishing LLC, 2017. https://doi.org/10.1063/1.4981190

[4] Didane, D. H., S. Mohd, Z. Subari, N. Rosly, MF Abdul Ghafir, and MF Mohd Masrom. "An aerodynamic performance analysis of a perforated wind turbine blade." In IOP Conference Series: Materials Science and Engineering, vol. 160, no. 1, p. 012039. IOP Publishing, 2016. https://doi.org/10.1088/1757-899X/160/1/012039

[5] Rozaim, Muhammad Faiz, Fazila Mohd Zawawi, Haslinda Mohamed Kamar, Nazri Kamsah, and Nur Safwati Mohd Nor. "Experimental study on performance of low speed wind turbine for application in Malaysia." Journal of Advanced Research in Fluid Mechanics and Thermal Sciences 26, no. 1 (2016): 20-28.

[6] Battisti, Lorenzo, A. Brighenti, E. Benini, and M. Raciti Castelli. "Analysis of different blade architectures on small VAWT performance." In Journal of Physics: Conference Series, vol. 753, no. 6, p. 062009. IOP Publishing, 2016. https://doi.org/10.1088/1742-6596/753/6/062009

[7] Didane, Djamal Hissein, Siti Masyafikah Maksud, Mohd Fadhli Zulkafli, Nurhayati Rosly, Syariful Syafiq Shamsudin, and Amir Khalid. "Performance investigation of a small Savonius-Darrius counter-rotating vertical-axis wind turbine." International Journal of Energy Research 44, no. 12 (2020): 9309-9316. https://doi.org/10.1002/er.4874

[8] Didane, D. H., S. M. Maksud, M. F. Zulkafli, N. Rosly, S. S. Shamsudin, and A. Khalid. "Experimental Study on the Performance of a Savonius-Darrius Counter-Rotating Vertical Axis Wind Turbine." In IOP Conference Series: Earth and Environmental Science, vol. 268, no. 1, p. 012060. IOP Publishing, 2019. https://doi.org/10.1088/1755$1315 / 268 / 1 / 012060$

[9] Didane, Djamal Hissein, Muhammad Amir Zafran Saipul Anuar, Mohd Faizal Mohideen Batcha, Kamil Abdullah, Mas Fawzi Mohd Ali, and Akmal Nizam Mohammed. "Simulation Study on the Performance of a Counter-rotating Savonius Vertical Axis Wind Turbine." CFD Letters 12, no. 4 (2020): 1-11. https://doi.org/10.37934/cfdl.12.4.111

[10] Al-Ghriybah, Mohanad, Mohd Fadhli Zulkafli, Djamal Hissein Didane, and Sofian Mohd. "Review of the recent power augmentation techniques for the Savonius wind turbines." Journal of Advanced Research in Fluid Mechanics and Thermal Sciences 60, no. 1 (2019): 71-84.

[11] Mathew, Sathyajith. Wind energy: fundamentals, resource analysis and economics. Springer, 2006.

[12] Venkatramakrishnan, Sri Ragunath, Jitendra K. Pandey, Amit Kumar Mondal, and Ashish Karn. "Low Speed Wind Turbines for Power Generation: A Review." Journal of Advanced Research in Fluid Mechanics and Thermal Sciences 67, no. 1 (2020): 146-169.

[13] Şahin, İzzet, and Adem Acir. "Numerical and experimental investigations of lift and drag performances of NACA 0015 wind turbine airfoil." International Journal of Materials, Mechanics and Manufacturing 3, no. 1 (2015): 22-25. https://doi.org/10.7763/IJMMM.2015.V3.159

[14] Miller, Steven D. "Lift, Drag and moment of a NACA 0015 Airfoil." Department of Aerospace engineering 28 (2008). 
[15] Graham IV, Henry Z., Chad Panther, Meagan Hubbell, Jay P. Wilhelm, Gerald M. Angle, and James E. Smith. "Airfoil selection for a straight bladed circulation controlled vertical axis wind turbine." In Energy Sustainability, vol. 48890, pp. 579-584. 2009. https://doi.org/10.1115/ES2009-90343

[16] Asr, Mahdi Torabi, Erfan Zal Nezhad, Faizal Mustapha, and Surjatin Wiriadidjaja. "Study on start-up characteristics of H-Darrieus vertical axis wind turbines comprising NACA 4-digit series blade airfoils." Energy 112 (2016): 528-537. https://doi.org/10.1016/i.energy.2016.06.059

[17] Raghunathan, S., and C. P. Tan. "Effect of blade profile on the performance of the Wells self-rectifying air turbine." International journal of heat and fluid flow 6, no. 1 (1985): 17-22. https://doi.org/10.1016/0142727X(85)90026-8

[18] Mohamed, M. H. "Performance investigation of H-rotor Darrieus turbine with new airfoil shapes." Energy 47, no. 1 (2012): 522-530. https://doi.org/10.1016/i.energy.2012.08.044

[19] Migliore, P. G. "Comparison of NACA 6-series and 4-digit airfoils for Darrieus wind turbines." Journal of Energy 7 , no. 4 (1983): 291-292. https://doi.org/10.2514/3.48083

[20] Tenguria, Nitin, N. D. Mittal, and Siraj Ahmed. "Investigation of blade performance of horizontal axis wind turbine based on blade element momentum theory (BEMT) using NACA airfoils." International Journal of Engineering, Science and Technology 2, no. 12 (2010). https://doi.org/10.4314/ijest.v2i12.64565

[21] Alquraishi, Balasem Abdulameer, Nor Zelawati Asmuin, Sofian Mohd, Wisam A. Abd Al-Wahid, and Akmal Nizam Mohammed. "Review on Diffuser Augmented Wind Turbine (DAWT)." International Journal of Integrated Engineering 11, no. 1 (2019). https://doi.org/10.30880/ijie.2019.11.01.021

[22] Jaat, Norrizam, Amir Khalid, Norrizal Mustaffa, Fathul Hakim Zulkifli, Norshuhaila Mohamed, Ridwan Saputra Nursal Sunar, Mahmod Abd Hakim Mohamad, and Djamal Didane. "Analysis of injection pressure and high ambient density of biodiesel spray using computational fluid dynamics." CFD Letters 11, no. 1 (2019): 28-39.

[23] Majunit, Nurul Izyan, Fazila M. Zawawi, Nur Safwati Mohd Nor, Haslinda Mohamed Kamar, and Nazri Kamsah. "Numerical investigation of vortex formation effect on horizontal axis wind turbine performance in low wind speed condition." Journal of Advanced Research In Fluid Mechanics And Thermal Sciences.

[24] Wolfe, Walter P., and Stuart S. Ochs. Predicting aerodynamic characteristic of typical wind turbine airfoils using CFD. No. SAND-96-2345. Sandia National Labs., Albuquerque, NM (United States), 1997. https://doi.org/10.2172/534484

[25] Langtry, Robin, Janusz Gola, and Florian Menter. "Predicting 2D airfoil and 3D wind turbine rotor performance using a transition model for general CFD codes." In 44th AIAA aerospace sciences meeting and exhibit, p. 395.2006. https://doi.org/10.2514/6.2006-395

[26] Chen, Jim Shih-Jiun, Zhi Chen, Saroj Biswas, Jiun-Jih Miau, and Cheng-Han Hsieh. "Torque and power coefficients of a vertical axis wind turbine with optimal pitch control." In Power Conference, vol. 49354, pp. 655-662. 2010. https://doi.org/10.1115/POWER2010-27224

[27] Carriveau, Rupp, ed. Fundamental and advanced topics in wind power. BoD-Books on Demand, 2011. https://doi.org/10.5772/731 